\title{
Teacher Preparedness for a Changing Demographic of Language Learners
}

\section{Nina Lee Webster and Angela Valeo}

English-language learners (ELLs) are becoming common in classrooms with Ontario's escalating immigration trends. Elementary school teachers are increasingly becoming responsible for meeting the needs of linguistically diverse children. This qualitative study explores current teacher preparation practices through preservice teachers' (PT) perspectives and explores how prepared primary-junior PTs are to teach ELLs in southwestern Ontario. Through a structured interview, six certified graduates shared descriptive experiences, knowledge, and beliefs. Findings indicate that although moving toward greater ELL awareness and inclusive mindsets, there is evidence that well-intentioned teachers lack the competence necessary for effective classroom practice.

La croissance de l'immigration en Ontario se traduit par la présence accrue d'apprenants d'anglais dans les salles de classe de la province. Les enseignants à l'élémentaire se voient de plus en plus souvent accorder la responsabilité de répondre aux besoins d'enfants d'origines linguistiques variées. Cette étude qualitative examine, d'une part, les pratiques en formation des enseignants par le biais des perspectives de stagiaires et, d'autre part, la mesure dans laquelle les stagiaires à l'élémentaire sont formés pour enseigner aux apprenants de l'anglais dans le sudouest de l'Ontario. Dans le cadre d'une entrevue structurée, six diplômés certifiés partagent une appréciation descriptive de leurs expériences, leurs connaissances et leurs croyances. Les résultats indiquent qu'en dépit d'une évolution vers une meilleure reconnaissance des apprenants d'anglais et une attitude mentale plus inclusive, il existe des éléments qui montrent que les enseignants bien intentionnés n'ont pas la compétence nécessaire pour être efficaces en salle de classe.

\section{Introduction}

Ontario is the province of choice for over $50 \%$ of newcomers to Canada (Chui, Tran, \& Maheux, 2007a, 2007b; People for Education, 2008). Immigration continues to fuel Ontario's population growth while significantly contributing to linguistic diversity. As immigration increases, the English-language learners (ELLs) will become increasingly common in regular classrooms. ELLs are the fastest growing segment of elementary students (Antunez, 2002; Buck, Mast, Ehlers, \& Franklin, 2005; Harper \& de Jong, 2004). The need to prepare teachers better for working with ELLs is widely recognized (Taylor \& Sobel, 2003). Studies have concluded that teachers graduating from edu- 
cation programs do not have the strategies necessary for simultaneous support of both academic content development and English-language growth (Buck et al.; Evans, Arnot-Hopffer, \& Jurich, 2005; Waxman \& Téllez, 2002). These teachers enter the field with limited cross-cultural knowledge and understanding of classroom challenges (Barnes, 2006; Buck et al.; Dorrington \& Ramirez-Smith, 1999; Harper \& de Jong; Taylor \& Sobel), and teachers are taught to understand diversity merely in terms of celebrations and the appreciation of differences. With limited knowledge, teachers are susceptible to misinterpreting the capabilities of ELLs (Buck et al.; McLaughlin, 1992), and ineffectual core courses yield low inclusion competence and low levels of ELL sensitivity, leading to premature assumptions and blinders with respect to the assets that ELLs bring to the learning of all children (Pappamihiel, 2004).

Many Ontario faculties of education are responding to the need to prepare future teachers for a rapidly growing population of ELLs in the regular classroom, but the effectiveness of these programs is unclear. One way to assess the effect of such programs is to explore the perceptions of recent graduates regarding their self-efficacy and training. Their perspectives are crucial indicators of the gains received from their teacher training programs. In addition, Pappamihiel (2004) claimed that preservice teachers' (PTs) perceptions of their self-efficacy may be the most accurate predictor of their future classroom behaviors, which means that it is crucial to investigate them. Many PTs feel inadequately prepared to teach ELLs effectively in general classrooms (Dianda, 1992; Flynn \& Hill, 2005; Meskill, 2005; Téllez \& Waxman, 2005; Youngs \& Youngs, 2001). Meskill found that many PTs were unaware of their responsibilities in educating ELLs due to a lack of emphasis in training. Taylor and Sobel stated that $73 \%$ of PTs identified student diversity as their greatest teaching challenge. Mujawamariya and Mahrouse (2004) provided deeper insights into this concern as PTs critiqued their own multicultural education. Many programs opt for a simple celebration of differences paradigm, which produces low levels of ELL competence. Although cultural inclusion and respect have been gained, PTs express a need for greater cultural content knowledge, explicit instruction with demonstrations, open discussion, practical teaching styles, problem-solving techniques, and opportunities to implement theory realistically (Barnes, 2006; Taylor \& Sobel; Valentine, 2006). These components are believed to contribute to ELL competence, yet are not apparent in the curriculum of many teacher education programs. Without adequate ELL training, PTs remain uncertain of their ability to integrate the needs of ELLs with curriculum goals, assessments, and supportive teaching (Emporia State University, 1994; Flynn \& Hill; Menken \& Antunez, 2001; Valentine). This study examines the perceptions and reflections of six recent graduates from Ontario faculties of education regarding their level of preparation for meeting the needs of ELL students. 


\section{Models of Education}

In Ontario, faculties of education are fairly autonomous institutions. Although the Ontario Ministry of Education has an interest in what faculties teach because their training of teachers affects the K-12 school population, they do not dictate what will be taught (personal communication, J. Nigro, Education Officer, Ministry of Education, July 23, 2010). The Ontario College of Teachers (OCT), the teaching profession's regulatory body that accredits programs, requires that methods, theory, and foundation courses be taught, but guidelines on the content of those courses is more general (Ontario College of Teachers Act, 1996, Regulation 347/02). In effect, each faculty of education in Ontario is free to determine the content of its courses and the method of their presentation. In addition to course work, the OCT also mandates a minimum of 40 days of practical teaching experience in schools ( Regulation 184/97).

\section{Common Teacher Education Curricula}

Three common teacher education curricula, including pedagogies and approaches, are explored in the literature. Positive features can be taken from each model. Culturally Responsive Teaching (CRT) focuses on training for academic success, cultural competence, and sociopolitical consciousness (Barnes, 2006). CRT is also known as culturally congruent/appropriate/compatible instruction, or culturally relevant teaching (Pappamihiel, 2004). It is evident that this approach is centered in culturally sensitive practice. Extended placements and courses focus on realistic settings, family interactions, and faculty debriefing (Barnes; Pappamihiel). The benefits of CRT include transforming attitudes and beliefs about diversity, a solid cultural knowledge base, reflection on actions and interactions, implementation of ELL skills, and internalizing roles in education. These benefits come with much effort because changing ingrained attitudes and beliefs is difficult. An added complexity involves altering known teaching practices to include ELLs.

Training All Teachers (TAT) focuses on establishing an enhanced understanding of the complex aspects of teaching ELLs (Meskill, 2005). Similar to CRT, TAT stresses the importance of gently confronting ingrained myths associated with the English language and language-learning (Meskill). The major components involve field work, group workshops with follow-up support, peer presentations, explicit teaching of cultural tolerance, and unlearning of racism. The benefits include a greater understanding of issues experienced by ELLs, increased appreciation of home experiences, practical strategies, cross-cultural empathy, and greater respect for differences. Regrettably, TAT programs maintain the lessons of most multicultural initiatives: only surface-level acceptance and respect for differences.

The Multicultural Education (ME) curriculum is implemented in many faculties of education across Canada (Mujawamariya \& Mahrouse, 2004). Its 
major objective is to prepare future teachers with the knowledge necessary to respond to the academic needs of all children. Multiple variations of this objective can be found in all Canadian faculties of education. For the PTs enrolled in Ottawa University's variation of the initiative, the curriculum is perceived as lacking because it does not specifically target ELLs (Majawamariya \& Mahrouse). All such models are based on a multicultural-focused curriculum, and there are many overlapping similarities and differences among them. Although each initiative is focused on improving the competence of PTs, none effectively meets its objectives.

Awareness of the existing possibilities and potential outcomes that exist in teacher education programming is necessary when evaluating the features of teacher education curricula. The various models presented above provide a broad overview of the wide-ranging strengths, challenges, and issues in training ELL teachers. CRT is particularly strong in its ability to transform attitudes and beliefs about the complexities of teaching English-language learners. ME focuses intensely on equity in the classroom. Overall, the strengths of transforming attitudes, understanding complexities, and establishing knowledge bases, are all crucial and necessary features of teacher preparation for ELLs. The interview questions used in this study attempted to capture to what extent many of the characteristics described in CRT, TAT, and ME were reflected in participants' experiences and appeared to contribute to overall program designs. In the study reported here, many of the facets described in CRT, TAT, and ME were individually reflected in various programs. However, the simultaneous presence of all necessary facets was not evidenced in any single program.

\section{Field Experiences}

In addition to course work, field experiences are crucial to a personal understanding of ELLs' needs (Barnes, 2006; Emporia State University, 1994; Pappamihiel, 2004; Valentine, 2006). Mastering experiences with professional support is vital to ELL competence. Pappamihiel declared that mastery experiences were the most influential source for the development of self-efficacy. PTs require exposure and opportunities for experience with ELLs (Youngs \& Youngs, 2001). However, for experiences to be valuable, they must be followed up by faculty or peer debriefing (Barnes; Meskill, 2005). Through this dialogue, students apply learned theories to their experiences, which adds meaning. Furthermore, as peers share their learning with others, they gain insight into real solutions and the consequences of particular behaviors (Meskill). This process contributes significantly to their learning, but is often overlooked in the curriculum. Discussing with colleagues is a required skill; classroom teachers will need to collaborate with other professionals in order to create classrooms conducive to the needs of children, including ELLs (Buck et al., 2005; Emporia State University). 


\section{Reflective Practice}

Reflective practice is also a critical component in effective programs. Reflective practice leads to the reinterpretation of teaching, thinking, and interactions with ELLs (Barnes, 2006; Buck et al., 2005; Cruz \& Patterson, 2005; Farrell, 2006). This component is oversimplified in many programs as a passive and superficial exercise, but in fact through reflective practice, PTs can explore their effect and role in the education system (Barnes; Dorrington \& Ramirez-Smith, 1999; Farrell). Through reflection, teachers are able to dismantle ingrained misconceptions that contribute to the oppression of minorities in education (Meskill, 2005). This process contributes to an increased understanding of culture and promotes the cultural sensitivity required by classroom teachers (Pappamihiel, 2004). Along with explicit instruction and demonstration, PTs require an in-depth understanding of their purpose. It is not sufficient to provide a list of strategies without any explanation of their necessity. Thus coursework must be aligned with realism in order to uphold the professional standards required in education (Taylor \& Sobel, 2003).

\section{Complexities of Working with ELLs}

Reforms aiming to prepare teachers better cannot be limited to a single course or left to the practicum (Meskill, 2005; Mujawamariya \& Mahrouse, 2004; Taylor \& Sobel, 2003). Similarly, optional courses do not do justice to the issues in education (Barnes, 2006; Mujawamariya \& Mahrouse). A cohesive systemic change including theories of language acquisition, diversity issues, and learning needs is required (Barnes, 2006; Buck et al., 2005; Emporia State University, 1994; Giambo \& Szecsi, 2005). It is urgent that programs include these authentic complexities if they claim to teach equity and inclusion (Buck et al.; Meskill).

Equally important is the removal of any negative components that may undermine curriculum objectives and teaching standards. Misconceptions, biases, and harmful attitudes about teaching ELLs continue to influence the curriculum. For example, such beliefs may blame ELLs for not fitting into the norms created by rigid instructional paradigms (Harper \& de Jong, 2004; Meskill, 2005), or the existing theoretical foundation may include notions that limit teachers' abilities to provide environments and lessons for ELLs (Harper \& de Jong). Mere exposure to multiculturalism is not sufficient. Lack of deeper understanding leads to misuse of accommodations and modifications, thus reinforcing biases. ELLs deserve opportunities for equitable outcomes and unbiased assessments that accurately evaluate learning such as alternative assessments that incorporate the use of portfolios. Without practical substitutes, ELLs are introduced into the classroom without the instruction or feedback required for effective learning of concepts or the development of academic language proficiency (Cummins, 2003; Dianda, 1992; Harper \& de Jong; Valentine, 2006). 


\section{Methodology}

\section{Research Design}

A qualitative research design combining interviews with a semistructured questionnaire was used in this study (see Appendix A for complete interview questions). This design allowed the data to emerge from the participants' responses. Participants were invited to discuss their thoughts, knowledge, and ideas openly about many of the interview topics (Creswell, 2005). We believed that this design was the most suitable for describing, analyzing, and interpreting a culture-sharing group (Creswell): the culture under investigation was that of elementary school teaching. The participants qualified as a culture-sharing group because they interacted and shared patterns of behavior (e.g., ELL strategies implemented in the classroom and the sharing of beliefs, attitudes, truths, myths, misconceptions, and expectations, Creswell). These behaviors and beliefs were developed or nurtured over the time spent in preservice education.

The interview process was guided by open-ended, pre-worded questions and a predetermined sequence. This interview type helped us to obtain simple demographic information and quickly established a general level of knowledge. The discussion then proceeded to an interview-guide approach where open-ended questions were used to obtain rich detail. A post-interview session was also conducted with each participant, during which the interviewer verified any initial interpretations made in the field. All interviews were 60 minutes in length and were audiotaped and transcribed. In addition, the interviewer took brief notes during each interview. Each participant received his or her interview transcript by e-mail and was asked for comments, clarification, and corrections if necessary. This procedure ensured the accuracy of the information recorded.

\section{Protection of Human Participants and Recruitment}

To protect the participants and research sites, all research plans were reviewed by the Research Ethics Board of Ryerson University (REB). The confidentiality and anonymity of participants were ensured throughout all phases of the study, and participants' names were dissociated from their responses during the recording and coding procedures. All names used here are pseudonyms.

Primary-junior (JK to grade 6) education trainees were recruited using purposeful and snowball sampling methods. All participants were recruited based on characteristics that met the requirements of the study, accessibility to the researcher, and willingness to be interviewed (Del Baso \& Lewis, 2001). This non-random sampling method allowed us to identify PTs who were close to graduating from the primary-junior division. Although the results of this sample cannot be generalized, the selected participants provide insight into understanding the central phenomenon of teacher preparation. 
Table 1

Participants' Practicum Experiences

\begin{tabular}{|c|c|c|c|}
\hline $\begin{array}{l}\text { Participant's } \\
\text { Pseudonym }\end{array}$ & $\begin{array}{l}\text { Number of } \\
\text { practica }(P) \\
\text { completed during } \\
\text { BEd Program }\end{array}$ & $\begin{array}{l}\text { Board and } \\
\text { grade level taught } \\
\text { (primary, JK-3, } \\
\text { junior, 3-6) }\end{array}$ & $\begin{array}{l}\text { Characteristics of } \\
\text { students taught (as } \\
\text { described by } \\
\text { participants) }\end{array}$ \\
\hline \multirow[t]{3}{*}{ Olivia Stevenson } & P1-2 weeks & $\begin{array}{l}\text { Public School Board } \\
\text { Primary Division }\end{array}$ & $\begin{array}{l}\text { Diverse classroom } \\
\text { (mainly Arabic, Hindi, } \\
\text { Urdu, and Punjabi } \\
\text { speakers) }\end{array}$ \\
\hline & P2 - 2 weeks & $\begin{array}{l}\text { Public School Board } \\
\text { Junior Division } \\
\text { (Gifted classroom) }\end{array}$ & $\begin{array}{l}\text { Well-established } \\
\text { middle-class } \\
\text { neighborhood }\end{array}$ \\
\hline & P3 - 3 weeks & $\begin{array}{l}\text { Public School Board } \\
\text { Junior Division } \\
\text { (Gifted classroom) }\end{array}$ & $\begin{array}{l}\text { Well-established } \\
\text { middle-class } \\
\text { neighborhood }\end{array}$ \\
\hline \multirow[t]{3}{*}{ Katie Long } & P1 - 5 weeks & $\begin{array}{l}\text { Private School } \\
\text { Primary Division }\end{array}$ & Affluent neighborhood \\
\hline & P2 -5 weeks & $\begin{array}{l}\text { Public School } \\
\text { Junior Division }\end{array}$ & $\begin{array}{l}\text { Inner-city with diverse } \\
\text { population }\end{array}$ \\
\hline & P3 - 5 weeks & $\begin{array}{l}\text { Private School } \\
\text { Primary Division }\end{array}$ & Affluent neighborhood \\
\hline \multirow[t]{3}{*}{ Mary Densmore } & $\begin{array}{l}\text { P1 - } 5 \text { Fridays of } \\
\text { observation leading } \\
\text { into 4-week block }\end{array}$ & $\begin{array}{l}\text { Public School Board } \\
\text { Primary Division }\end{array}$ & $\begin{array}{l}\text { Diverse classroom } \\
\text { (Vietnamese, Chinese } \\
\text { and Spanish speakers) }\end{array}$ \\
\hline & $\begin{array}{l}\text { P2 }-5 \text { Fridays of } \\
\text { observation leading } \\
\text { into 4-week block }\end{array}$ & $\begin{array}{l}\text { Public School Board } \\
\text { Junior Division }\end{array}$ & $\begin{array}{l}\text { White, European } \\
\text { backgrounds }\end{array}$ \\
\hline & P3 - 5 weeks & Public School Board & $\begin{array}{l}\text { Learning Enrichment } \\
\text { Academic Program } \\
\text { [LEAP] (considerable } \\
\text { number of ELL students) }\end{array}$ \\
\hline \multirow[t]{2}{*}{ Tina Goodwin } & P1 - 4-week block & $\begin{array}{l}\text { Public School Board } \\
\text { Primary Division }\end{array}$ & $\begin{array}{l}\text { Affluent/white } \\
\text { neighborhood (only two } \\
\text { students of Asian } \\
\text { backgrounds in class) }\end{array}$ \\
\hline & P2 - 4-week block & $\begin{array}{l}\text { Public School Board } \\
\text { Junior Division }\end{array}$ & $\begin{array}{l}\text { Special Education class } \\
\text { (very diverse- } \\
\text { considerable patois } \\
\text { spoken) }\end{array}$ \\
\hline
\end{tabular}


Table 1 (Continued)

Participants' Practicum Experiences

\begin{tabular}{llll}
\hline $\begin{array}{l}\text { Participant's } \\
\text { Pseudonym }\end{array}$ & $\begin{array}{l}\text { Number of } \\
\text { practica }(P) \\
\text { completed during } \\
\text { BEd Program }\end{array}$ & $\begin{array}{l}\text { Board and } \\
\text { grade level taught } \\
\text { (primary, JK-3, } \\
\text { junior, 3-6) }\end{array}$ & $\begin{array}{l}\text { Characteristics of } \\
\text { students taught (as } \\
\text { described by } \\
\text { participants) }\end{array}$ \\
\hline Frances Newman & $\mathrm{P} 1-4$-week block & $\begin{array}{l}\text { Catholic School Board } \\
\text { Primary Division }\end{array}$ & $\begin{array}{l}\text { (Mainly Caucasian with } \\
\text { little racial and linguistic } \\
\text { diversity. })\end{array}$ \\
\hline Linda Cornwall & $\mathrm{P} 1-5$-week block & $\begin{array}{l}\text { Public School Board } \\
\text { Junior Division }\end{array}$ & $\begin{array}{l}\text { Core French program } \\
\text { (Considerable diversity) }\end{array}$ \\
\hline P2 -4 weeks & Junior Division & $\begin{array}{l}\text { (A few recently } \\
\text { immigrated students, } \\
\text { but predominantly white) }\end{array}$ \\
& P3 -6 weeks & Primary Division & $\begin{array}{l}\text { Very diverse } \\
\text { (Considerable number } \\
\text { of new immigrants) } \\
\text { Considered to be the } \\
\text { least diverse of her } \\
\text { experiences. } \\
\text { (Predominantly white } \\
\text { neighborhood) }\end{array}$ \\
\hline
\end{tabular}

\section{Participant Demographics}

We chose the population of recent PT graduates because they were newly trained and recently certified, and their knowledge was most relevant to the intent of the study. A total of six participants were recruited for this investigation. All participants had recently completed a 2007-2008 southwestern Ontario faculty of education program in the primary-junior division. All the research participants were women, and none had any certification related to education apart from their recently obtained Bachelor of Education degree and teacher certification from the Ontario College of Teachers (see Table 1).

\section{Data Analysis}

Data analysis procedures were begun in the field in the form of reflexive notes during data-collection. These pieces of field information began the organization process. The data collected were then organized using flat coding and further synthesized using hierarchical coding (Creswell, 2003). Once the hierarchical coding was established, all data in each category were summarized with extracted descriptive information for each theme. 


\section{Limitations of the Study}

Owing to the nature of exploratory research, this study has particular limitations. Because the sample was non-randomly chosen, the results may not be generalizable to the whole population: the results of this study will apply only to the sample of individuals used. Nevertheless, the findings are a useful indication of the effectiveness of teacher preparation programs. A relatively small sample was used because qualitative research standards rely on the quality of data collected rather than quantity and elicits large pieces of descriptive information from a small group of motivated participants. The participants in this study were eager to share their in-depth opinions, experiences, and thoughts. However, it should also be noted that the participants' depictions and contributions are inconsistent in their level of detail. This may be the result of the interviewer's rapport with some participants, as well as particular personality traits. Some participants revealed more than others in their interview responses and so are utilized more in this article. A few participants were more narrowly focused in their interpretations of the interview questions and also in the responses that they provided.

\section{Findings and Discussion}

It is commonly believed that ELL-related knowledge is the special domain of ESL/ELL specialists; yet such knowledge has become necessary for all teachers who plan to educate children successfully in Ontario schools. In order to understand how well prepared these recent teaching graduates felt about their readiness to teach ELLs on graduation, we asked the participants to provide their perspectives on their faculty of education's courses and content related to ELLs and English as a second language.

\section{Lack of Mandatory Courses}

Overall, no mandatory courses were based on ELL instruction; instead, sessions or lectures based in ELL content were embedded in mandatory courses. The only ELL course available was an elective that was mentioned by two graduates. Participants who had experienced the periodic sessions and lectures agreed unanimously that the content was undoubtedly an overview as opposed to an in-depth exploration. Several of the participants noted that little class time was spent on ELL issues. For many, this consisted of a oneday class or a three-hour session in a language arts class. All participants also noted that the use of strategies for working with ELL children was a focus in these sessions. In Mary's case, someone other than the course instructor came in to talk about ELL issues and required the students to peruse an Ontario government document. She noted:

We only had, like, two classes where a teacher came in to talk to us about ESL kids ... In terms of course content: "This book that's pro- 
vided by the government it's called ... Many Roots, Many Voices ... they gave that to us and then we had to go through it and look at what are the strategies that you can use with ELLs and how a majority of our students are ELL learners so ... these strategies should apply to all of them.

Interestingly, Mary felt that the strategies to be used with ELL students were the same for all, thus defining ELL students' needs as a homogeneous category. For Katie, as seen below, the strategies learned seemed to be more general, with a focus on relationship-building:

We learned different strategies on how to be inclusive, what teachers can do to encourage students, to motivate ... and how we can help parents to build trust in teachers, students as well in that case.

Linda completed a course on topics related to diversity, but her comments revealed a superficial and tentative presentation of the issues. She noted:

We did a course, not that I remember any of it, it was, like, diversity like learners course and I guess that would relate the most ... I would probably say that [my undergraduate program] taught me more than I learned there. Course content: I just remember reading articles just about how to break things down I guess and ... allowing them to have that language in the classroom and not forbidding them to speak that or write in that language if that helps them to formulate their thoughts, like they can write in both ... and then we can just talk about it together, and it's important not to, like, shun who they are and where they come from 'cause then they won't want to learn at all.

It appears that the focus of content for Linda included recognition and validation of the ELL child's home language. Although this is a first step in any ELL program, there appears to have been little discussion about the significance of this approach for developing and supporting English-language skills. For Frances, the topic was discussed over a series of classes throughout the year, and she also noted the offering of an extracurricular course devoted to ELL issues. But once again, there was the sense of a broad, overview approach toward teaching about ELL instruction:

Frances: We had a ... seminar basically where they took random, very random days to talk about ESL or ELL so I didn't have one particular course that addressed it. It was maybe over the course of the year, maybe four or five, three-hour classes were dedicated to discussing that, there was an ELL course that was offered as your extracurricular course, but I didn't take that one. In terms of course 
content: We learned a lot about ways to accommodate them in the classroom but it was very broad ... and we did activities ... and learning about information, and learning techniques such as including visuals, or hand gestures, very basic ... if I had to sit down and work with a group of ELLs, I don't know if I would know a lot about it.

Frances' comment touched on a popular approach toward introducing material about children whose needs differ from those of the main stream known as the infusion model wherein content is touched on throughout a number of classes over the course of the term. It was clear from Frances' comments that she did not feel that she knew very much and that this model was not effective for her.

\section{Single Mandatory Course versus Infusion Approach}

According to the literature, infusing content into existing courses is not in itself enough to prepare PTs for working with ELLs in the classroom. Romi and Leyser (2006) found that many universities worldwide had begun to infuse content regarding children with special needs; yet the addition of some content is not effective. The infused content must be in-depth and also requires a practical component for optimal effectiveness (Romi \& Leyser). All the participants agreed that in general, diversity topics were infused and focused on throughout all mandatory courses. A range of diversity issues were discussed in these courses, including gender stereotypes, color, homophobia, upper- and middle-class biases, family background, and family units. However, even when a wide range of diversity is emphasized in the multicultural education focus, the literature notes that teacher education programs are not preparing teachers to deal with the linguistic diversity in classrooms (Gonzalez \& Darling-Hammond, 2000; Reiff \& Cannella, 1992) and that cultural sensitivity in itself is inadequate to allow prospective teachers to work effectively with ELLs (Dorrington \& Ramirez-Smith, 1999). Two participants criticized the lack of ELL content in their mandatory courses on societies. The exclusion of ELL content was disappointing to these teachers, and they questioned the reason for its absence. Although the literature suggests that preparation programs should recognize the importance of and need for incorporating ELL preparation for all prospective teachers (Gonzalez \& Darling-Hammond), based on the findings of this study, it is evident that minimal action has been taken.

For Olivia, as cited below, teaching ELLs was "touched upon," and it appears to have had more breadth than the others in that some theory was introduced. She observed,

We touched upon it on a course ... so there was a one-day lecture, like, a one-day period, spent on talking about ELL needs and a ... we did workshops and it talked about ELLs again. We learned about, 
well, we went through the stages of language development and ... they figured that, they assumed that we already have some background in theory so we talked about strategies and ways to adapt and a little bit where to get resources from. My professor ... actually showed us quite valuable techniques, strategies that he would use in Reading Recovery that could be applicable to an ELL.

Of particular interest in Olivia's comment is the reference to the use of strategies from Reading Recovery to work with ELL children. It is noteworthy that reading-recovery strategies were devised for use not with ELL children, but rather with children identified as being at risk for delays in learning to read. This emphasis on using strategies for children with at-risk needs was also evident in Tina's comment.

Well, we had language class, but again, it was just maybe one threehour session was spent on ELLs ... [In terms of course content] just basically how ... how learning the letters and learning the phonetics and the rules is difficult because ... English is so complex. And just different strategies for helping them learn language the same way you would for a child who was developmentally, like, delayed in language.

Clearly it is illogical to believe that ELL children's needs are similar to those of children with special needs or reading delays. This was an interesting finding in the light of the current overrepresentation of children of minority backgrounds in special education programs (Artiles, Kozleski, Trent, Osher, \& Ortiz, 2010; Garcia \& Ortiz, 2006).

All the participants believed that a mandatory course on ELL teaching would have been valuable. Parallel to the literature, most of the participants believed that a large, authentic experience along with course content would be the most effective method of enhancing ELL competence in teacher preparation programs (Dorrington \& Ramirez-Smith, 1999; Montgomery, Roberts, \& Growe, 2003). The following comments illustrate this belief.

Mary: I would have liked to have ... a whole course on that but unfortunately we didn't ... was just a few hours, which I thought was ridiculous ... just give us more direct instructions ... in terms of how to teach them and how to assess them and because what we do with English language learners can be applied to all students ... so we really should have like a whole, one whole course on it.

Mary felt that the strategies learned in an ELL course could be generalized and used with other students. Tina also stressed the need for a mandatory course. 
I was lucky that in my placement, it wasn't really an issue and I say lucky because I don't think I would have really been prepared ... we haven't really learned enough to know what to do, and if I was to be in [a school] where $90 \%$ of the kids in that school are ELLs, I'd be screwed! We definitely need a mandatory course in education.

Overall, all participants agreed that there needed to be more ELL content in their preparation and that a single elective course on ELLs or dismissing the content altogether was ineffective. The participants in this study had strong views on this issue; the following two comments reflect the general tone of the conversation.

Katie: I think a mandatory course would be more beneficial because the classes didn't even talk about ELLs as much as that one [elective], and we learned so much about what we can do ... my friends and I were talking about it as well, how it should be mandatory.

Tina: I think that a lot of the time it gets lost when it gets infused ... separate, just like they need separate time to learn English, we need separate time of how to teach. How do I get this kid speaking in my classroom? How do I encourage them and say, OK, speak ... what do I do? And so I think a case-by-case scenario would be helpful, and then have, like, tools for us not only to help set up our classroom ... What do you do when language is a barrier also? So it would be really good to have some strategies.

Participants believed that a mandatory course could be more in depth and could provide more linguistic knowledge than if such content were lightly infused throughout. Interestingly, one participant believed that a mandatory course would be better because she was concerned with professors' ability to infuse the content. Despite these responses, according to Farrell (2006), a single course is not enough for effective ELL preparation. When this information is isolated from other knowledge, the new information is minimal among other well-established beliefs. Overall, a greater ELL focus is required for a well-rounded program.

The only participant who believed that both should be implemented without leniency toward either stated the following.

Linda: I think both should be done, and that's how I felt it was done in my program where that discussion topic was brought up throughout the science, the gym, the language, everything. Because there won't only be ... it is yah, it'll, they will be in all your subjects right, so you have to deal with it depending on what you are teaching. 
It is evident in this statement that Linda was highly aware of the prevalence of ELLs in the classroom in all academic subjects. In accordance with the literature, all possible actions should be taken in teacher education programs to enhance ELL competence and quality teaching. The literature suggests that neither alone is effective, yet each has its benefits.

\section{Perceptions of Self-Efficacy}

Participants in this study described their ELL sessions as what the literature deems a "typical introductory ELL workshop" for professionals outside the ESL/ELL "specialization" (Harper \& de Jong, 2004). In introductory workshops, the theoretical foundation necessary for ELL preparation may be oversimplified through emphasizing the overlap between first- and second-language-learning and ignoring the important differences (Dianda, 1992; Gonzalez \& Darling-Hammond, 2000; Harper \& de Jong, 2004). The complex components of English-language learning can thus be condensed to the most basic pieces of point-form information. When crucial ELL preparation information is condensed to such minimalism, many teachers falsely feel at ease, believing that they will be able to learn what they need in the field with minimal groundwork. This, however, did not appear to be the case with the graduates in this study, who did not feel at ease about their ability to teach ELL children. This is unfortunate, for the literature shows that when teachers are highly prepared for the profession, they will have a high level of confidence in their teaching skills and abilities. The more competent teachers feel following preparation, the more successful they will be in the classroom (Dorrington \& Ramirez-Smith, 1999; Farrell, 2006; Gándara, Maxwell-Jolly, \& Driscoll, 2005; Verdugo \& Flores, 2007). As Farrell states, attitude is the foundation for all other success. Attitudes of self-efficacy can have more influence on future teaching methods than any information that trainees receive during preparation. The teachers in this study demonstrated tenuous confidence in their abilities to teach ELL children adequately, while noting the challenges that they believed they would face. Tina appeared to be the most confident of the group and commented,

I think that I am getting there. I would say that I am maybe at like a $50-60 \%$, preparation percentage, but if I was really in, if I was in it ... like instantaneously my brain would be going and thinking about, OK, well what do they need, how do I prepare, who do I talk to? And then it would slowly increase. And yah, then I'd be more prepared.

But Tina was also aware that her knowledge was not solid and hoped that it would be strengthened with practice. Mary, on the other hand, felt that she lacked confidence specifically in the area of the assessment of ELL children, and she noted, 
In terms of assessments or evaluations, that's my weak point ... I need more practice in that, so I'm not very confident in that ... and we should have had more class hours for ... We only had like maybe two classes on assessment ... that was it.

Current assessment methods are exceedingly monocultural. The content used in standardized assessments may present messages that are culturally biased and that elicit negative feelings (Reiff \& Cannella, 1992; Youngs \& Youngs, 2001). Without exposure to alternatives and content sensitivity, teachers maintain a cycle of inaccurate assessments. Teacher education needs to provide the knowledge, understanding, and practice necessary to adapt assessments to meet individual needs (Emporia State University, 1994; Menken \& Antunez, 2001; Téllez \& Waxman, 2005; Verdugo \& Flores, 2007). It is imperative that teachers know how to adapt assessments appropriately without a relying on surrounding professionals, because these are not always available or knowledgeable. Teachers themselves are obligated to record progress and to know if they are meeting a child's language and educational needs (Verdugo \& Flores). In this study, the lack of confidence in assessment practices was also echoed by Tina.

I hate giving my kids a grade, assessment is one of my, my biggest things. I am, I'm terrified of giving a kid a mark on their report card and I'm going to have a parent knocking on my door saying, "My kid doesn't deserve this mark," or you know, and then having to sit there and justify it and even if I have work samples, and even if I have, you know, objectives for the grade given, well, like what if that's not good enough? Like what do I do? That's one thing that I'm really worried about; I'm worried about assessment.

Olivia and Frances believed that they had some knowledge, but were also reassured that they could seek outside help once they were in the classroom.

Olivia: I feel, confident, enough that ... if ... I have some knowledge right now ... when I start, when I have my own classroom, I will know where to go to get support.

Frances: I am not sure, I don't know ... it would definitely be a challenge, definitely be a challenge. Would I be able to do it? I think, I think yes. It would, I would probably rely a lot on resources, and rely a lot on people within my school, community. But I think in the end, I would be able to do it, maybe not perfectly the first time, but ... eventually through experiencing it and pooling all my resources around me, I think it would be good. 
Olivia and Frances were relying on receiving inservice professional development for ELLs when necessary in future teaching environments. This expectation is not surprising, as Dorrington and Ramirez-Smith (1999) also found that many respondents expected their employers to provide training rather than being responsible for their own professional development before encountering such a situation. To explore this issue further, Menken and Antunez (2001) and Montgomery et al. (2003) found these types of inservice workshops to be short term and to expose teachers only superficially to ELLrelated concepts without providing the in-depth knowledge or connections necessary for lasting effects on teaching practice. Also, although Olivia and Frances claimed that they would seek professional support, the literature contradicts this expectation. Evans et al. (2005) found that knowledge about ELL supports was often not valued or sought and that in some cases classroom teachers went so far as to resent support for them in their schools.

Currently preservice and inservice training focuses heavily on establishing English proficiency and classroom strategies rather than on the who, how, and why of English-language teaching and learning (Cruz \& Patterson, 2005; Gonzalez \& Darling-Hammond, 2000; Montgomery et al., 2003). The fact that PTs are willing to rely on inservice development in this way uncovers their assumptions about what is deemed important preparation (Evans et al., 2005). Frances also identified concerns about issues of fairness and exclusion because of the attention she might have to give one group over another in order to meet their needs. She noted,

There is so much to accommodate to, I'd be afraid that if I am accommodating too much to one child, that I would be missing something from another child, or if I am spending time on one, it's like spending time on one curriculum you are missing a part of the other curriculum, like, it's so broad that. I think that $b-$, maybe not a barrier but a challenge would be to, to do it consistently and effectively.

Issues of fairness are a recurring concern among teachers, who often feel that some children may unfairly receive more of the teacher's time because of their needs (Dorrington \& Ramirez-Smith, 1999).

\section{Misconceptions Regarding ELL Children's Language Needs}

Although it is difficult to foresee all future difficulties, it is unmistakable that PTs do foresee some challenges. Therefore, PTs need to be given more opportunities to explore areas of concern in order to resolve fears and enhance self-efficacy beliefs (Alfred, 1994). There is a good indication that many PTs have not reached a comfort level that enables them to feel confident in their ability to work with ELLs as with other children (Dorrington \& RamirezSmith, 1999; Flynn \& Hill, 2005). However, while noting their lack of preparation, two of the PTs in this study also expressed the belief that their role in 
directly teaching ELL children would be minimal because simply exposing children to the regular language arts curriculum with a few accommodations would be beneficial. Four participants agreed that exposure would enhance the pace and ability to learn English. The following is Tina's comment reflecting this belief.
Exposure and ... because it's an active process, so not just assuming that by sitting in a classroom that the students are going to pick it up, but by ... making accommodations to lessons to ... assist the lan- guage learners in the classroom, so let's say, you know, you're doing a lesson ... have things labeled so that they are seeing the word, they are hearing the word, and then, you know, ensuring that you know spelling; spelling is a part of your, of your literacy program.

The two remaining participants refuted the exposure claim by taking into account consideration for the child's comprehension of the language, learning context, possibility of culture-shock, and readiness to learn the language. Frances noted,

Really depends on the child, and it also depends on the context of where they are, I am trying to think of an example ... for whatever reason it might even be cult-, maybe a culture shock that they are not ready ... to learn the language, but they have been placed in a situation where they need it.

Exposure to English must be paired with motivation, purpose, and explicit teaching of the functions, genres, and phonological, grammatical, and morphological aspects of the language (Harper \& de Jong, 2004). Exposure without interaction, feedback, and opportunities to respond is simply not sufficient for learning a language. However, it is apparent from this study and the literature at large that teacher preparation still lacks sufficient depth on the topics of English-language learning and teaching, which results in graduates who lack ELL expertise and competence (Dorrington \& RamirezSmith, 1999; Gándara et al., 2005). Trainee teachers require deep subject matter about ELLs to assist them in achieving grade-level standards (Gándara et al.; Menken \& Antunez, 2001). Without explicit instruction, PTs are unaware and cannot access the academic knowledge and skills embodied in the curriculum (Menken \& Antunez; Montgomery et al., 2003). PTs also lack a thorough understanding of language-acquisition processes, which limits their comprehension of needs and overall efficacy.

So what would the participants in this study like to see taught? How could their education have been different? First, it appears that they would like to have received more detailed content to enhance their own teaching competence. This finding is congruent with Waxman and Téllez's (2002) 
study, which also recognized the need for more information about helping ELLs meet high academic standards. But the most significant answer to this question comes from the participants' discussion of practicum field placements.

\section{Field Placement}

Placements are designed to provide PTs with a practical component where they can translate course content into practice. Field experiences also provide learning opportunities because PTs are able to observe successful teachers in practice. PTs with successful role models have the chance to observe the implementation of effective teaching strategies and to experiment with their own strategies while being provided with constructive feedback (Cruz \& Patterson, 2005; Dorrington \& Ramirez-Smith, 1999; Menken \& Antunez, 2001; Romi \& Leyser, 2006). However, PTs require realistic classroom experiences with linguistically diverse people. Linguistic differences and intercultural communications are intimidating and uncomfortable to those who have not yet encountered these experiences either first or second hand (Dorrington \& Ramirez-Smith; Evans et al., 2005; Reiff \& Cannella, 1992; Youngs \& Youngs, 2001). Frances and Linda commented on their desire to know more before graduating, with specific reference to knowledge gained from direct contact working with an ELL child. They noted,

Frances: I took initiative ... it wasn't something that was told to you, like I, it was more I had to test things out, and see what worked with this child, but ... it was helpful in that sense, but it wasn't like my associate teacher sat me down and said OK, this is how you are going to do this, and it was a lot of testing and seeing what worked.

Linda: What would be great is have a placement where you have to be in a situation where you were working with someone ... that correlates specifically to what to do in these situations when you are dealing with ELLs.

Mary believed that she could not have acquired some of her ELL knowledge without her ELL placement. She said,

I would say now more confident than I was before had my internship because I learned a lot from this teacher, she was really good ... she integrated, like, subjects linked to curriculum expectations ... for ELL learners so I was really shocked that she was able to do that.

Practical experiences allow PTs to explore theories, models, strategies, research findings, policies, and classroom issues under experienced supervision. This idea was emphasized by Olivia, who believed that text material should be taught alongside practical experiences. She commented, 
I definitely think that it would be, it would be ... valuable; however, if you don't have practical experience working with children who are ELLs, I feel like that course would be less valuable because when you are reading strategies out of textbook and you've never tried them, its great, I mean they are still valuable, and you are gaining valuable information and knowledge, but if you cannot try them at all, put them to practice, then when you get into the field you are going to have to learn it all over again. So I think that it would be valuable if it had a large practical component to it.

For Frances, in-class lectures and textbooks were not essential, and she said,

I think I would just want the experience actually working one-onone and learning the techniques, rather than just being told ... I want to see it, and I want to be able to do it ... So if it was... a course where it ... gave me information, but at the same time had a practical component, I think that would be ... great.

The participants in this study clearly valued field experience over course work and believed that it could go a long way in providing useful knowledge.

\section{Conclusion}

Our intention in this article was solely to test the waters of teacher preparation programs in Ontario regarding the training of teachers for working with ELL children. To this end, the results are consistent with much of the research in the United States, which shows a strong disconnect between teacher education programs and the feelings of self-efficacy that graduating teachers express with respect to meeting the needs of ELLs in today's classrooms. The participants in this study wanted more linguistic training and in-depth understanding of the language-acquisition process. All felt that the general approach to course work in an Ontario faculty of education had failed to provide them with the skills that they needed to feel confident when working with ELL students. Many also favored learning about ELLs in the field during practicum placements and described a strong desire to have these skills modeled.

This study also raised several questions about some of the perceptions that the PTs in the study held such as the idea that simple exposure to the English-language curriculum was enough to allow ELL children to become proficient in English, or that ELL learners could be regarded as a homogeneous group for the purposes of instruction. Perhaps the most questionable view that the participants in this study raised was the idea that ELL children's needs were similar to those of children with disabilities. Perhaps these misperceptions were a result of the participants' general lack of in-depth knowledge, but they require further investigation. 
The question of how faculties of education should change in order to close this disconnect is still unclear. The participants in this study expressed a need for greater content knowledge, explicit instruction with demonstrations, practical teaching strategies, and opportunities to implement theory realistically. The ability of faculties of education to integrate these components into a one-year program - with only 40 days of practicum, over which many Faculties have minimal control is questionable. In addition, the value that the participants attached to their practicum placements cannot be overlooked, and this raises the question of whether the Bachelor of Education program in Ontario should be extended to two years, thereby making more time available for both practicum placements and in-class work, which could truly involve discussion and peer debriefing. A longer training period for teachers would also allow for adding a mandatory course on ELL learners.

\section{The Authors}

Nina Lee Webster is a part-time instructor with the School of Early Childhood Education at Ryerson University and supervises field education students. She is also a doctoral student in educational studies at Brock University with a focus on cognition and learning. She holds a master's degree from Ryerson University's Master's in Early Childhood Studies, a Bachelor of Education from Brock University, and a Bachelor of Arts from Ryerson University; she is also a member of the Ontario College of Teachers.

Angela Valeo is an assistant professor in the School of Early Childhood Education at Ryerson University. She holds a doctorate from York University with a focus on diversity and special needs. Angela was a teacher with the Toronto Catholic School Board before coming to Ryerson.

\section{References}

Alfred, I. (1994, March). ESL in the mainstream: Challenges and possibilities. Paper presented at the annual meeting of the Teachers of English to Speakers of Other Languages, Baltimore. (ERIC Document Reproduction Service No. ED 385120)

Antunez, B. (2002). The preparation and professional development of teachers of English language learners. ERIC Digest. Washington, DC: ERIC Clearinghouse on Teaching and Teacher Education. (ERIC Document Reproduction Service No. ED 477724)

Artiles, A.J., Kozleski, E.B., Trent, S.C., Osher, D., \& Ortiz, A. (2010). Justifying and explaining disproportionality, 1968-2008: A critique of underlying views of culture. Exceptional Children, 76(3), 279-299.

Barnes, C.J. (2006). Preparing pre-service teachers to teach in a culturally responsive way. Negro Educational Review, 57(1-2), 85-100.

Buck, G., Mast, C., Ehlers, N., \& Franklin, E. (2005). Preparing teachers to create a mainstream science classroom conductive to the needs of English-language learners: A feminist action research project. Journal of Research in Science Teaching, 42(9), 1013-1031.

Chui, T., Tran, K., \& Maheux, H. (2007a). 2006 Census: Immigration in Canada: A portrait of the foreign-born population, 2006 Census, findings. Retrieved January 14, 2008, from: http://www12.statcan.ca/english/census06/analysis/immcit/highlights.cfm

Chui, T., Tran, K., \& Maheux, H. (2007b). Immigration in Canada: A portrait of the foreign born population, 2006 Census. Retrieved January 14, 2008, from: http:/ / www12.statcan.ca/english/census06/analysis/immcit/pdf/97-557XIE2006001.pdf

Creswell, J.W. (2003). Research design: Qualitative, quantitative, and mixed method approaches. Thousand Oaks, CA: Sage. 
Creswell, J.W. (2005). Educational research. Planning, conducting and evaluating quantitative and qualitative research (2nd ed.) Upper Saddle River, N J: Pearson Merrill Prentice Hall.

Cruz, B.C., \& Patterson, J.M. (2005). Cross-cultural simulations in teacher education: Developing empathy and understanding. Multicultural Perspectives, 7(2), 40-47.

Cummins, J. (2003). BICS and CALP: Origins and rationale for the distinction. In C.B. Paulston \& G.R. Tucker (Eds.), Sociolinguistics: The essential readings (pp. 322-328). London: Blackwell.

Del Baso, M., \& Lewis, A.D. (2001). First steps: A guide to social research. Toronto, ON: Thomas Nelson Learning.

Dianda, M. (1992). Promoting beginning teachers' success in teaching linguistically diverse students: A synthesis of relevant knowledge and practice. San Francisco, CA: Southwest Regional Educational Laboratory. (ERIC Document Reproduction Service No. ED 346104)

Dorrington, A.E.L., \& Ramirez-Smith, C. (1999). Teacher educators: A minority perspective on preparing majority preservice teachers for diverse classrooms. (ERIC Document Reproduction Service No. ED 430955)

Emporia State University. (1994). Competencies, skills, and knowledge teacher education programs need to teach the inclusion teacher (BBB16772). Emporia, KS: Author.

Evans, C., Arnot-Hopffer, E., \& Jurich, D. (2005). Making ends meet: Bringing bilingual education and mainstream students together in preservice teacher education. Equity and Excellence in Education, 38, 75-88.

Farrell, T.S.C. (2006). "The teacher is an octopus": Uncovering preservice English language teachers' prior beliefs through metaphor analysis. RELC Journal, 37(2), 236-248.

Flynn, K., \& Hill, J. (2005, December). English language learners: A growing population. Policy Brief: Mid-Continent Research for Education and Learning, 1-12. Retrieved, March 23, 2008, from: http://www.mcrel.org/PDF/PolicyBriefs/5052PI_PBEnglishLanguageLearners.pdf

Gándara, P.C., Maxwell-Jolly, J., \& Driscoll, A. (2005). Listening to teachers of English language learners: A survey of California teachers' challenges, experiences, and professional development needs. Santa Cruz, CA: Center for the Future of Teaching and Learning.

Garcia, S.B., \& Ortiz, A.A. (2006). Preventing disproportionate representation: Culturally and linguistically responsive prereferral interventions. Teaching Exceptional Children, 38(4), 64-68.

Giambo, D., \& Szecsi, T. (2005). Opening up to the issues: Preparing preservice teachers to work effectively with English language learners. Childhood Education, 82(2), 107-111.

Gonzalez, J.E., \& Darling-Hammond, L. (2000). Programs that prepare teachers to work effectively with students learning English. Washington, DC: ERIC Clearinghouse on Languages and Linguistics. (ERIC Document Reproduction Service No. ED 447724)

Harper, C., \& de Jong, E. (2004). Misconceptions about teaching English-language learners. Journal of Adolescent and Adult Literacy, 48(2), 152-162.

McLaughlin, B. (1992). Myths and misconceptions about second language learners: What every teacher needs to unlearn. Educational Practice Report 5: National Centre for Research on Cultural Diversity and Second Language Learning. Retrieved March 1, 2011 from: http:/ / people.ucsc.edu/ ktellez/epr5.htm

Menken, K., \& Antunez, B. (2001). An overview of the preparation and certification of teachers working with limited English proficient (LEP) students. Washington, DC: National Clearinghouse for Bilingual Education. (ERIC Document Reproduction Service No. ED 455231)

Meskill, C. (2005). Infusing English language learner issues throughout professional educator curricula: The training all teacher project. Teachers College Record, 107(4), 739-756.

Montgomery, P.S., Roberts, M., \& Growe, R. (2003). English language learners: An issue of educational equity. (ERIC Document Reproduction Service No. ED 482753)

Mujawamariya, D., \& Mahrouse, G. (2004). Multicultural education in Canadian preservice programs: Teacher candidates' perspectives. Alberta Journal of Educational Research, 50, 336-353. 
Ontario College of Teachers Act, 1996. Retrieved March 8, 2011, from: http:/ / www.elaws.gov.on.ca/html/statutes/english/elaws_statutes_96o12_e.htm

Pappamihiel, E.N. (2004). Hugs and smiles: Demonstrating caring in a multicultural early childhood classroom. Early Child Development and Care, 174(6), 539-548.

People for Education. (2008). Ontario's urban and suburban schools: A discussion paper on the schools we need in the 21st century. Toronto, ON: Author. Retrieved March 12, 2011, from: http://www.peopleforeducation.com/urban $\% \mathrm{E} 2 \% 80 \% 90$ suburban $\% \mathrm{E} 2 \% 80 \% 90$ schools

Reiff, J.C., \& Cannella, G.S. (1992, February). Preparing teachers for cultural diversity: Rhetoric or reality? Paper presented at the annual meeting of the Association of Teacher Educators, Orlando. (ERIC Document Reproduction Service No. ED 350267)

Romi, S., \& Leyser, Y. (2006). Exploring inclusion preservice training needs: A study of variables associated with attitudes and self-efficacy beliefs. European Journal of Special Needs Education, 21(1), 85- 105.

Taylor, S.V., \& Sobel, D.M. (2003). Rich contexts to emphasize social justice in teacher education: Curriculum and pedagogy in professional development schools. Equity and Excellence in Education, 36(3), 249-258.

Téllez, K., \& Waxman, H.C. (2005). Effective professional development programs for teachers of English language learners. Laboratory for Student Success (LSS), Mid-Atlantic Regional Educational Laboratory, 803, 1-2.

Valentine, S. (2006). Addressing diversity in teacher education programs. Education, 127(2), 196-202.

Verdugo, R.R., \& Flores, B. (2007). English-language learners: Key issues. Education and Urban Society, 39(2), 167-193.

Waxman, H.C., \& Téllez, K. (2002). Research synthesis on effective teaching practices for English language learners. Philadelphia, PA: Temple University. (ERIC Document Reproduction Service No. ED 474821)

Youngs, C.S., \& Youngs, Jr., G.A. (2001). Predictors of mainstream teachers' attitudes toward ESL students. TESOL Quarterly, 35, 97-120.

\section{Appendix}

\section{Interview Questions}

1. In what program did you receive your undergraduate degree? Do you have any additional certifications related to education?

2. How many practicum blocks did you have? Tell me about your practicum experiences.

Probes:

- How long was each placement block?

- Would you describe the classroom as diverse?

- Were there different languages present in the classroom?

3. What does the term, "English Language Learner" mean to you [Please define.]

4. Which faculty of education courses were related to English language learners or ESL? Were these courses mandatory or elective? What, in relation to ELLs/ESL did you learn about?

Probes:

- Overview of the topics or in-depth? 
5. In total, how many hours of the program would you estimate were spent on learning about:

- Practical ELL strategies

- Diversity issues

- Classroom learning needs for linguistically diverse children

- Second language acquisition

6. Are there any benefits to having a first language other than English in Canada? Probes:

- What are some of the benefits for the child? How does this benefit all children?

7. How would you develop a relationship with a newly arrived ELL in your future classroom?

Probes:

- What types of strategies or methods would you use?

- How will you make this child feel comfortable in the learning environment?

8. How will you communicate with ELLs who have no or limited English proficiency?

9. What ELL classroom strategies do you plan to plan to use with ELLs in the future? Why?

Probes:

- How do you know these strategies are effective?

- Where were these strategies learned?

10. What other ELL tools or resources would you use? Why and where did you learn these from?

Probes:

- Book titles, resource lists, workshops, conferences, placement/personal experience.

11. What are your expectations of school ESL supports and what are their responsibilities?

Probes:

- What are your responsibilities in relation to these professionals and services?

12. How valuable would a mandatory course on ELL teaching be? Probes:

- Would this be more effective than infusing the topic of ELLs through-out existing courses?

13. What kind of classroom barriers do you anticipate in future teaching? Probes:

- What is your greatest concern? (E.g., cultural differences, language barriers, time constraints, parents...)

14. Do you feel that all of your graduating peers know enough about ELLs and working with ELLs to be an effective educator with them in the classroom? Probes:

- Why or why not? Please elaborate.

- How could this situation be changed?

15. Do you feel confident in your own abilities to fulfil the multiple roles and responsibilities of the classroom teacher for ELLs?

Probes:

- This includes planning and implementing curriculum standards, accommodations to teaching strategies, creating meaningful classroom engagement and true assessments or evaluation. 
16. What recommendations do you have for your faculty of education program, with regards to ELLs?

Probes:

- Is there anything you think you should be taught but isn't?

- Is there anything you wish they taught you? 